\title{
Editorial
}

\section{Taking Time to Enjoy Some Coffee! Adding Mindfulness to the Curriculum}

\author{
Audrey C Tolouian* \\ The University of Texas at El Paso School of Nursing, USA
}

*Corresponding author: Audrey C Tolouian, Clinical Assistant Professor, The University of Texas at El Paso School of Nursing, USA.
Received Date: July 12, 2020

Published Date: July 23, 2020

\section{Editorial}

Nursing students and graduate nurses are notoriously stressed, with high impact exams and the need to learn mass amounts of information plus clinical skills, creates an area ripe for tension [1]. Add in a pandemic halfway through the semester, and anxiety levels increase even more. Once they graduate, however, this stress does not go away, it often intensifies for the first couple of years postgraduation [2]. Current information shows once they graduate, only $18 \%$ of nurses feel they are prepared with adequate self-care skills to manage the effects caused from day to day events of the work environment. Nursing school curriculums typically do not help prepare students to deal with the stressors of their jobs, with only $6 \%$ of nursing schools providing any type of mindfulness skills in the curriculum $[3,4]$.

Some issues which transpired due to quarantining were: online exams being compromised, students lost clinical time, and even the simulated clinical time, was made virtual. Through all of this, the students were at a loss. There was increased confusion on the part of students and faculty. Information was disseminated as quickly as possible, but this was not enough, the data seemed to change several times a day- the students needed more support. The students lost their community. Not only were they going to school full time, they were now taking care of their spouses and children full time, and then, they were told they had to become home schoolteachers, creating an atmosphere of overwhelming chaos [5]. In order to provide some virtual face to face contact, online virtual office hours were created.
During this time, it was observed that the students were just really needing a space to connect, they would log in, just to have some conversation, not always pertaining to nursing school. At this same time, a friend of mine had created a virtual Coffee Shop for his coaching business, I would watch the recording from afar-due to the time zone difference- as they gathered, drank coffee and had a nice time, laughing and supporting each other. I was chatting with another faculty about how the students seemed to be struggling, needed some skills, and were hankering for contact, and she suggested implementing the virtual Coffee Shop idea into my class, and Wallah! the "Coffee Shop" came to life!

Globally, the Father of Mindfulness is Nhat Hanh, he taught people to find the joy in life's simple pleasures. Here in the United States John Kabat-Zinn, in known for bringing awareness to the mindfulness movement. He is the creator of the University of Massachusetts' Medical Clinic's Stress Reduction and Relaxation Program, currently called the mindfulness-based stress reduction (MBSR) which seems to be the gold standard for mindfulness teachings at this time. His definition of mindfulness is "the awareness that arises from paying attention, on purpose, in the present moment and non-judgmentally" [6].

Once a week, a virtual session called the "Coffee Shop" was created, as a, optional safe place for students to come hang out in a semi-structured environment. Since the academic course was a research course, all of the activities have been based in nursing research. Topics are focused on self -care, mindfulness, and fun..... 
traditional nursing school academic topics are not included. Taking the Father of Mindfulness's approach, we take time and together enjoy a cup of coffee. How it works is each week there is a Coffee Shop topic that is self-care or mindfulness related, introduced on Monday. During the week the students and faculty engage in the written discussion on a platform similar to traditional social media, post pictures and have a discussion about the topic. Then, on Friday we gather in a virtual platform and do an activity based on the topic from the week.

The very first week we chatted about stress relief, since stress seemed to be the major topic talked about by the students. Many people posted about fitness, hiking, their pets, all things that they, themselves, did to relax a bit during this crazy time- we were just learning about COVID-19, so people were anxious. And again this conversation got me thinking about nurses and their lack of skills or the self- permission to help take time for their own well-being [4].

So, I searched a bit more to find ways that the students could learn to take care of themselves at the same time as build some sense of community with their peers, albeit a virtual one. The following week, a meditation coach logged in with us and led a guided meditation (she helped us visualize being in nature and taught us some breathing techniques that we can use at another time). The students loved this, there was so much feedback about how nice it was and how good they felt afterward. One student called and said she wished we could have it every week, another wrote to me about her experience, and thanked me for helping her develop a self-care skill which she felt she had been lacking and would use from now on. The students learned some new skills and reinforced the idea that meditation can help improve cognition, insight and improve awareness [7]. So, needless to say, we are having another session later this summer.

During one of the discussions the following week, a student mentioned that he was an artist, and his mood was reflected in his colour choices. This prompted a bit of research into colour use and research studies. I found a few studies that showed if students coloured mandalas before exams it helped to increase focus on the exam, and they performed better [8]. So, the next week we coloured mandalas and the students shared them on the discussion. What was so amazing is that students, shared their art and it created a nice week of people sharing their art and talking about being creative. The students really opened up and shared a deeper part of themselves and allowed others to see another side of them.

The following week was "bring your pet to class day". It is amazing how people enjoy being engaged in the class with pets. The students have dogs, cats, and several types of other pets. It has opened up a whole discussion on how the pets help to keep people calm, make them laugh and help them take their minds off of school [9]. The pictures really show the personalities of the animals, and how special they are to the students.

These are just a few of the topics that we have talked about in our Coffee Shop, we will eventually have 12 or so topics as we finish out the summer, we will have yoga, tai chi and a few more. Over all, the students have given positive feedback throughout the past two semesters say they enjoy the Coffee Shop time and have learned a few ways to relax [10]. Each semester, it has evolved, and will continue to evolve based on student feedback and participation. I am constantly getting emails and texts from my students thanking me for it. It has been a great way to get to know my students and have some fun with them, while we are all having a challenging time in the virtual and real world but this has helped to maintain a sense of community with the students, I have built better relationships with the students- by letting my guard down and relaxing with them, and we have learned a thing or two about each other that we never would have learned in a face to face environment. This platform is easy to implement in other types of environments, such as offices or hospitals. I think I have enjoyed the time with the students and learning new wellness skills, just as much as they have! So, take a break and grab a cup of coffee with your students, it is so worth it!

\section{Acknowledgement}

None.

\section{Conflict of Interest}

The authors declare that there is no conflict of interest.

\section{References}

1. Cane P (2011) Capacitar: Healing trauma, empowering wellness, a multicultural popular education approach to healing trauma. Capacitar International, Inc. Santa Cruz, Canada.

2. Marthiensen R, Sedgwick M, Crowder R (2019) Effects of a brief mindfulness intervention on after-degree nursing student stress. J Nurs Educ 58(3): 165-168.

3. Mealer M, Cochran K, Moss M (2006) Preparing graduate nurses for the psychological stress and trauma of working as an acute care bedside nurse: Results of a national survey. American Journal of Respiratory and Critical Care Medicine 2018;197: A3623.

4. Penque S (2019) Mindfulness to promote nurses' well-being. Nurs Manage 50(5): 38-44.

5. (2020) Coping with stress. Centers for Disease Control and Prevention.

6. Kabat-Zinn J (2013) Full catastrophe living: Using the wisdom of your body and mind to face stress, pain, and illness (2nd edn). Random House Publishing Group.

7. Spadaro K, Hunker D (2016) Exploring the effects of an online asynchronous mindfulness meditation intervention with nursing students on stress, mood, and cognition: A descriptive study. Nurse Educ Today 39: 163-169.

8. Carsley D, Heath N (2020) Effectiveness of mindfulness-based coloring for university students' test anxiety. Journal of American College Health 68(5): 518-527. 
9. Anderson D (2018) The effect of animal-assisted therapy on nursing student anxiety. University of Kansas, Dissertation.
10. Song Y, Lindquist R (2015) Effects of mindfulness-based stress reduction on depression, anxiety, stress and mindfulness in Korean nursing students. Nurse Educ Today 35(1): 86-90. 